\section{THE WRIGHTS SERVICE WITH FREE DELIVERY}

With its practices' needs at the heart of everything that it does, Wrights firmly believes in putting customers first. Offering incredible value for money and an unbeatable client-centric service, Wrights pro-

vides dentists with what Wrights they want, when they me Deval
stpryico

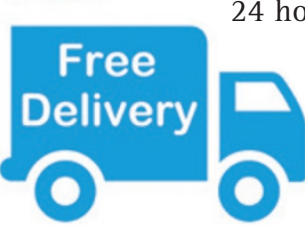

\section{4 hours.}

With the additional benefits of a simple, time sav-

ing ordering system, free delivery on everything and no charge on re-stocking returns, Wrights really is the national distributor with a difference.

Ahmed Zaher, Head of Marketing for Wrights said: 'As an independent company, our aim will always be to support hard-working practices and to maximise their business potential.

'We will continue to ensure we offer an efficient service - including features such as free next day delivery - and we remain dedicated in meeting the requirements of each and every one of our practices.' To find out more on how Wrights could help you, contact the team today on 0800668899 or visit www.wright-cottrell.co.uk.

\section{THE ELITE OF SELF-ADHE- SIVE RESIN CEMENTS}

Kerr's Maxcem Elite came out on top in recent research comparing the bond strength of various selfadhesive dental cements to human dentine and enamel. Following a 2015 laboratory evaluation, Brown and colleagues concluded that new and improved Maxcem Elite, a selfetch, self-adhesive resin cement for indirect restorations, '...showed superior adhesive bonding results across all tested products in regards to shear bond strength.'
In addition to its superior bond strength, Maxcem Elite offers:

- Easy handling

- Simple procedures

- Universal application.

The material's optimised

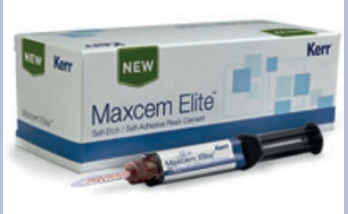
resin matrix and filler sys-

tems also improve wettability, allowing for immediate light curing and better shelf-life stability.

Also worthy of note is that its proprietary redox initiator system eliminates the inherent discolouration of benzoyl peroxide/tertiary amine initiator systems for a more aesthetic restoration.

For further information, call 01733 892292, email kerruk@kerrhawe.com or visit www.kerrdental.co.uk.

\title{
SPECIALISED KITS FOR COSMETIC TREATMENTS
}

Tandex provides quality aftercare kits for maintaining good levels of oral hygiene during and after cosmetic treatments.

Now more than ever your patients have access to unprecedented levels of cosmetic dentistry and it is important that you are ready to provide them with the equipment they need to thoroughly look after their teeth throughout these treatments.

Tandex offers both orthodontic and implant kits that have all the necessary tools and adjuncts to ensure your patients can comply with any specific aftercare instruction - from gentle brushes for sensitive areas of the gingiva to interproximal brushes to ensure a thorough clean.

The kits include detailed user guides that comprehensively instruct patients on optimum cleaning protocols. Produced in cooperation with dentists and hygienists the in-depth information allows patients to use the products as they were intended, for easily achievable and excellent results.
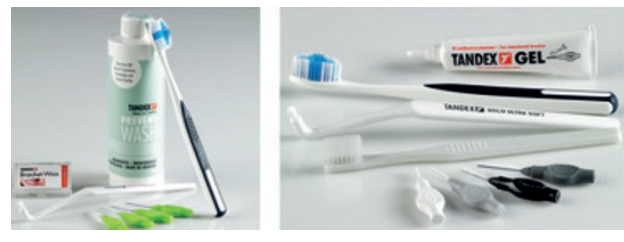

Ensure you are ready to guide your patients to uphold strong standards of oral hygiene during and after cosmetic treatments by offering Tandex's range of specialist kits. For more information on Tandex's range of products call +45 473810 01, email tandex@tandex.dk or visit www.tandex.dk.

\section{US NEWS: NEW INVESTOR OPTION FOR SMALLER BUSINESSES}

Raising capital to pay for expansion plans can sometimes be a major hurdle for smaller companies that aren't publicly traded on the stock exchanges. But in the USA a new investor option is making the path less formidable for these smaller businesses with big dreams.

Revised rules adopted by the US Securities and Exchange Commission went into effect over the summer, allowing companies to sell up to $\$ 50$ million of securities in a 12-month period, meaning that everyday citizens can become the investors.

Sun Dental Labs, a Florida-based company, was one of the first in the USA to receive SEC approval to move forward with a securities offering under the change. Diasti Diasti, Chief Executive Officer of Sun Dental
Labs, saw the SEC rule change as the perfect opportunity for the company, which manufactures and distributes custom dental devices, such as crowns, bridges, partials, dentures, implants and orthodontic devices. Although based in Florida, Sun Dental Labs also has facilities in the United Kingdom, Sweden, France, the Netherlands, Germany and China.

Diasti said: 'We are excited about this because it gives us easier access to capital without having to be listed on the trading markets. Anyone can invest in this company, so this democratises investing.

'We've developed a digital workflow that lets the dentist scan the mouth to get an impression, which will provide a more accurate fit, is more comfortable for the patient and results in a quicker turnaround. Our plan is to [use the funds raised by selling securities to] purchase additional manufacturing equipment and technology, and acquire a dental lab facility in Latin America.

'In the next 10 years, no one will go to a dentist unless that dentist's office is digital. The industry is changing and we plan to be a big part of that.'

Visit www.sundentallabs.com for further information. 